\title{
$\mu$-Opioid Receptors in the Nucleus Accumbens Shell Region Mediate the Effects of Amphetamine on Inhibitory Control But Not Impulsive Choice
}

\author{
Joost Wiskerke, Dustin Schetters, Inge E. van Es, Yvar van Mourik, Bjørnar R. 0. den Hollander, \\ Anton N. M. Schoffelmeer, and Tommy Pattij \\ Department of Anatomy and Neurosciences, Neuroscience Campus Amsterdam, Vrije Universiteit University Medical Center, 1081 BT Amsterdam, \\ The Netherlands
}

Acute challenges with psychostimulants such as amphetamine affect impulsive behavior in both animals and humans. With regard to amphetamine, it is important to unravel how this drug affects impulsivity since it is not only a widely abused recreational drug but also regularly prescribed to ameliorate maladaptive impulsivity. Therefore, we studied the effects of amphetamine in two rat models of impulsivity, the five-choice serial reaction time task and the delayed-reward task, providing measures of inhibitory control and impulsive choice, respectively. We focused on the role of opioid receptor activation in amphetamine-induced impulsivity as there is ample evidence indicating an important role for endogenous opioids in several behavioral and neurochemical effects of amphetamine. Results showed that amphetamine-induced inhibitory control deficits were dose-dependently attenuated by the preferential $\mu$-opioid receptor antagonist naloxone, but not by the selective $\delta$-opioid receptor antagonist naltrindole or $\kappa$-opioid receptor antagonist nor-BNI (norbinaltorphimine dihydrochloride). In contrast, naloxone did not affect amphetamine-induced improvements in impulsive decision making. Naloxone also completely prevented inhibitory control deficits induced by GBR 12909 [1-(2-[bis(4-fluorophenyl)methoxy] ethyl)-4-(3-phenylpropyl)piperazine dihydrochloride], a selective dopamine transporter inhibitor. Intracranial infusions of naloxone, the selective $\mu$-opioid receptor antagonist CTAP (H-D-Phe-Cys-Tyr-D-Trp-Arg-Thr-Pen-Thr- $\mathrm{NH}_{2}$ ), morphine, and the selective $\mu$-opioid receptor agonist DAMGO $\left(\left[\mathrm{D}-\mathrm{Ala}^{2}, \mathrm{~N}-\mathrm{Me}-\mathrm{Phe}^{4}, \mathrm{Gly}^{5}\right.\right.$-ol]-enkephalin acetate salt) revealed that $\mu$-opioid receptor activation in the shell rather than the core subregion of the nucleus accumbens (NAc) modulates inhibitory control and subserves the effect of amphetamine thereon. Together, these results indicate an important role for NAc shell $\mu$-opioid receptors in the regulation of inhibitory control, probably via an interaction between these receptors and the mesolimbic dopamine system.

\section{Introduction}

Impulsivity is a multifaceted construct covering various, mostly independent, behavioral measures ranging from impulsive actions (e.g., disturbed inhibitory control or response inhibition) to impulsive decisions (e.g., delay aversion) (Evenden, 1999; Moeller et al., 2001; Winstanley et al., 2006; Pattij and Vanderschuren, 2008). Maladaptive impulsivity has been implicated in a wide range of psychiatric disorders, including attention-deficit/ hyperactivity disorder (ADHD), bipolar disorders, and substance use disorders (American Psychiatric Association, 2000). Psychostimulant drugs such as methylphenidate and amphetamine targeting monoaminergic neurotransmission are nowadays leading prescription drugs to treat ADHD (Elia et al., 1999; Kutcher et al., 2004). Particularly for amphetamine, it is important to understand the neuronal mechanisms by which this psychostimulant

Received Sept. 13, 2010; revised 0ct. 22, 2010; accepted 0ct. 23, 2010.

This work was supported by Dutch Top Institute Pharma Grant T5-107-1.

Correspondence should be addressed to Dr. Tommy Pattij, Department of Anatomy and Neurosciences, Neuroscience Campus Amsterdam, Vrije Universiteit University Medical Center, Van der Boechorststraat 7, 1081 BT Amsterdam, The Netherlands. E-mail: t.pattij@vumc.nl.

DOI:10.1523/JNEUROSCI.4794-10.2011

Copyright $\odot 2011$ the authors $\quad 0270-6474 / 11 / 310262-11 \$ 15.00 / 0$ affects different aspects of impulsivity as it is also a widely abused addictive compound. In both humans and rodents, acute challenges with amphetamine impair inhibitory control, at least when operationalized as the inability to restrain inappropriate behavior (Cole and Robbins, 1987, 1989; Fillmore et al., 2003; van Gaalen et al., 2006a, 2009; Pattij et al., 2007), and reduce impulsive choice, often measured as intolerance to delayed gratification or delay aversion (Wade et al., 2000; de Wit et al., 2002; Winstanley et al., 2003, 2005; van Gaalen et al., 2006b).

Although the effects of amphetamine on impulsivity depend on enhanced dopamine (DA) transmission (Cole and Robbins, 1987, 1989; Winstanley et al., 2003, 2005; van Gaalen et al., 2006b, 2009; Pattij et al., 2007), other neurotransmitter systems may also play crucial roles in regulating impulsive behavior, including endogenous opioid systems (Madden et al., 1997; Kieres et al., 2004; Mitchell et al., 2007; Boettiger et al., 2009; Love et al., 2009; Olmstead et al., 2009; Pattij et al., 2009; Zacny and de Wit, 2009). Indeed, there is ample evidence showing that amphetamine activates endogenous opioid systems (Wang and McGinty, 1995, 1996; Olive et al., 2001; Gonzalez-Nicolini et al., 2003), and the effects of amphetamine on DA release and behavioral measures including locomotion, reward, and amphetamine-induced rein- 
statement of amphetamine seeking involve opioid transmission (Trujillo et al., 1991; Hooks et al., 1992; Schad et al., 1995; Jayaram-Lindström et al., 2004, 2008; Häggkvist et al., 2009). This raises the question as to whether endogenous opioids also mediate amphetamine-induced impulsivity.

The nucleus accumbens (NAc) contains a dense expression of opioid receptors, particularly $\mu$ - and $\kappa$-opioid receptors (Mansour et al., 1987; Dilts and Kalivas, 1989; Svingos et al., 1997). This region modulates (amphetamine-induced changes in) inhibitory control and impulsive choice (Cole and Robbins, 1987, 1989; Cardinal et al., 2001; Christakou et al., 2004), with putative differential involvement of the NAc shell and core subregions (Pattij et al., 2007; Murphy et al., 2008). The present aim was to investigate the role of opioid receptors in the NAc shell and core in amphetamine-induced changes in two aspects of impulsivity, inhibitory control and impulsive choice. To that end, we used systemic and intracranial drug injections to manipulate behavioral performance in the five-choice serial reaction time task (5CSRTT) and delayed-reward task (DRT), measuring inhibitory control and impulsive choice, respectively.

\section{Materials and Methods}

Subjects. Male Wistar rats were obtained from Harlan CPB. At the start of the experiments, animals weighed $\sim 250 \mathrm{~g}$ and were housed two per cage in macrolon cages $(42.5 \times 26.6 \times 18.5 \mathrm{~cm}$; length by width by height) under a reversed $12 \mathrm{~h}$ light/dark cycle (lights on at 7:00 P.M.) at controlled room temperature $\left(21 \pm 2^{\circ} \mathrm{C}\right)$ and relative humidity of $60 \pm 15 \%$. Animals were maintained at $\sim 90 \%$ of their free-feeding weight, starting 1 week before the beginning of the experiments by restricting the amount of standard rodent food pellets (Harlan Teklad Global Diet). Water was available ad libitum throughout the entire experiment. All experiments were conducted with the approval of the animal ethical committee of Vrije Universiteit.

Drugs. (+)-Amphetamine sulfate and morphine hydrochloride (both OPG), as well as naloxone hydrochloride, H-D-Phe-Cys-Tyr-D-Trp-ArgThr-Pen-Thr- $\mathrm{NH}_{2}$ (CTAP), and [D-Ala ${ }^{2}, \mathrm{~N}-\mathrm{Me}-\mathrm{Phe}^{4}, \mathrm{Gly}^{5}$-ol]-enkephalin acetate salt (DAMGO) (all Sigma-Aldrich), and nor-binaltorphimine dihydrochloride (nor-BNI) (Tocris Bioscience) were dissolved in sterile saline. 1-(2-[Bis(4-fluorophenyl)methoxy] ethyl)-4-(3-phenylpropyl) piperazine dihydrochloride (GBR 12909 dihydrochloride) and naltrindole hydrochloride (both Sigma-Aldrich) were dissolved in sterile water. Drug doses and injection times were based on previous studies. nor-BNI was injected 22-24 h before testing, naloxone and naltrindole $30 \mathrm{~min}$ before testing, and amphetamine and GBR $1290920 \mathrm{~min}$ before testing. In the intracranial infusion experiments, systemic amphetamine/saline was administered immediately after intracranial infusion (i.e., $15 \mathrm{~min}$ before testing). Drugs were freshly prepared each day before testing and injected intraperitoneally in a volume of $1 \mathrm{ml} / \mathrm{kg}$ body weight or infused intracranially in a volume of $0.5 \mu \mathrm{l} /$ hemisphere according to a Latin square within-subjects design for all experiments except for the tests with nor-BNI. As nor-BNI is very long-acting, we first conducted 2 test days to assess the effects of vehicle and amphetamine (in random order) in a group of rats, and then split the group of rats into two subgroups with equal behavioral results during the first 2 test days (amphetamine data not shown for nor-BNI alone group) to test the effects of nor-BNI alone or in combination with amphetamine on a final third test day. Drug tests were conducted on Tuesdays and Fridays with baseline training sessions on the other weekdays. Before the first test day, all animals had been habituated twice to intraperitoneal saline injections. Importantly, behavioral sensitization might occur to the behavioral effects of amphetamine, even after single exposure to $5 \mathrm{mg} / \mathrm{kg}$, a 10 -fold higher dose than used here (Vanderschuren et al., 1999). However, as shown previously in our laboratory, in an experimental design similar to those used in the present study the behavioral response to $0.5 \mathrm{mg} / \mathrm{kg}$ amphetamine was not altered by repeated exposure to this dose of amphetamine (van Gaalen et al., 2006b). Moreover, to limit the number of amphetamine challenges each subject received, in the present study animals were only tested in one particular drug Latin square except for animals used in the intracranial infusion experiments.

Apparatus. Experiments were conducted in identical rat five hole nose poke operant chambers with stainless-steel grid floors (MED-NPW-5L; MED Associates) housed in sound-insulating and ventilated cubicles. Set in the curved wall of each box was an array of five holes. Each nose poke unit was equipped with an infrared detector and a yellow light-emitting diode stimulus light. Rodent food pellets ( $45 \mathrm{mg}$; Formula P; Bio-Serv) could be delivered at the opposite wall via a dispenser. In addition, a white house light could illuminate the chamber. A computer equipped with MED-PC, version 1.17 (MED Associates), controlled experimental sessions and recorded data. Animals were tested once daily from Monday until Friday, during the dark phase of the light/dark cycle.

Behavioral procedures. Separate groups of animals were trained for each experiment ( $n=16$ for systemic pharmacology; $n=10$ and $n=12$ for intracranial infusions), unless stated otherwise. For all paradigms, similar habituation and magazine training protocols were followed. This protocol consisted of a habituation exposure to the operant chambers for 20 min with the house light on and the food cup containing three food pellets during the first session. Subsequently, in the next two sessions, in total 75 pellets were delivered with an average delay of $15 \mathrm{~s}$ to allow the animals to associate the sound of pellet delivery with reward.

Five-choice serial reaction time task. A detailed description of the 5-CSRTT behavioral procedure in our laboratory has been provided previously (van Gaalen et al., 2006a). In short, rats were trained to detect and respond to a brief visual stimulus in one of five nose poke units to obtain a food reward. Each session terminated after 100 trials or $30 \mathrm{~min}$, whichever occurred first. Initially, the duration of this stimulus was $32 \mathrm{~s}$ and was gradually decreased to $1 \mathrm{~s}$ over sessions until animals reached stable baseline performance (accuracy, $>80 \%$ correct choice and $<20 \%$ errors of omission). Responding during stimulus presentation or within the limited hold (LH) period of $2 \mathrm{~s}$ was counted as a correct response. Incorrect, premature responses during the fixed $5 \mathrm{~s}$ intertrial interval, and errors of omission (no responses or a response after the $\mathrm{LH}$ ) did not lead to the delivery of a food reward and resulted in a $5 \mathrm{~s}$ time-out period during which the house light was extinguished. Perseverative responses after correct choice (i.e., repeated responding during stimulus presentation into any stimulus unit after correct stimulus detection and before pellet collection) were measured but did not have any programmed consequences. The primary measure for inhibitory control was the number of premature responses. In some cases, however, the percentage of premature responses before stimulus onset, calculated as [premature responses/(premature + correct + incorrect + perseverative responses) $]^{\star} 100$ was used as an additional measure. This measure was only calculated to control for significant drug-induced increments in omission errors and amphetamine-induced differences in the number of premature responses between NAc core and shell drug infusion groups. Furthermore, the following other behavioral parameters were measured that reflect task performance: (1) accurate choice (i.e., percentage correct responses calculated as [number correct trials/(correct + incorrect trials) $]^{\star} 100$ ); (2) omission errors (i.e., the total number of omitted trials during a session); (3) the total number of perseverative responses after correct choice, measuring aspects of compulsive behavior (Robbins, 2002); (4) latency to make a correct choice (i.e., the mean time between stimulus onset and nose poke in the illuminated unit); and (5) feeder latency (i.e., the latency to collect a pellet after correct choice).

Delayed-reward paradigm. The delayed-reward paradigm used in our laboratory has been described previously (van Gaalen et al., 2006b). Briefly, in the final stages of training and during drug testing, a session was divided into five blocks of 12 trials; each block started with 2 forcedchoice trials. Each rat received a left forced and a right forced trial. The order of these was counterbalanced between subjects. In the next 10 trials, the animals had a free choice and both the left and right units were illuminated. Poking into one position resulted in the immediate delivery of a small reinforcer (one food pellet), whereas a nose poke into the other position resulted in the delivery of a large, but delayed, reinforcer (four food pellets). If an animal omitted a response during this choice phase within $10 \mathrm{~s}$, an intertrial interval was initiated and the trial was counted as an omission. The position associated with the small and large reinforcer 
was always the same for each individual, and counterbalanced for the group of rats. Delays for the large reinforcer progressively increased within a session per block of 12 trials as follows: $0,5,10,20$, and $40 \mathrm{~s}$. Responding into nonilluminated units during the test was recorded but had no additional programmed consequences. The behavioral measure to assess task performance (i.e., the percentage preference for the large reinforcer as a function of delay) was calculated as the number of choices for the large reinforcer/(number choices large + small reinforcers $)^{\star} 100$. Furthermore, we calculated the total number of omitted choice trials per block of 10 trials within a session.

Surgery. On stable baseline performance in the 5-CSRTT, separate groups of animals were prepared for cannulation surgery by terminating the food restriction and providing ad libitum access to food for $3 \mathrm{~d}$ before surgery. Animals were anesthetized using a combination of xylazine (Rompun; Bayer AG; $7 \mathrm{mg} / \mathrm{kg}$, i.p.) and ketamine (Alfasan; $100 \mathrm{mg} / \mathrm{kg}$, i.m.), and then placed in a stereotaxic instrument (David Kopf Instruments) for bilateral placement of indwelling guide cannulae (Plastics One). Guide cannulae were positioned $1 \mathrm{~mm}$ above the NAc core ( $8^{\circ}$ angle relative to the midline sagittal plane of the skull), or the NAc shell ( $12^{\circ}$ angle), and anchored to the skull with four stainlesssteel screws and dental acrylic cement. Cannulae were inserted under a sagittal angle to prevent possible intrusion of the lateral ventricles, thereby minimizing the possibility of drug diffusion into the lateral ventricles. The coordinates (in millimeters, relative to bregma) used for placement of intracranial cannulae were anteroposterior $(\mathrm{A} / \mathrm{P})+2.3$, mediolateral $(\mathrm{M} / \mathrm{L}) \pm 2.7$ to midline, dorsoventral $(\mathrm{D} / \mathrm{V})-6.4$ ventral to skull for the NAc core groups, $\mathrm{A} / \mathrm{P}+2.4, \mathrm{M} / \mathrm{L} \pm 2.6$, and $\mathrm{D} / \mathrm{V}-7.4$ ventral to skull for the NAc shell groups, calculated from Paxinos and Watson (1998). The tooth bar was set to $-2.5 \mathrm{~mm}$. Rats received 0.5 $\mathrm{ml} / \mathrm{kg}$ analgesic Ketofen (1\%; Merial) and $0.3 \mathrm{ml} / \mathrm{kg}$ antibiotic Baytril $(2.5 \%$; Bayer $)$ at the end of surgery. After surgery, the animals were housed individually and had ad libitum access to food for a week before retraining in the 5-CSRTT.

Infusion procedure. Intracranial infusions were performed when stable baseline performance was reestablished. Initially, during a sham infusion session, animals were habituated to insertion of the injectors [31 gauge and extending $1( \pm 0.04) \mathrm{mm}$ beyond the guide cannulae; Plastics One; model C316] into the guide cannulae. During the infusion studies, drugs were infused on Tuesdays and Fridays, with baseline training sessions in between during which no infusions were conducted. Rats were bilaterally infused with either saline, naloxone, CTAP, morphine, or DAMGO over a period of $60 \mathrm{~s}$ at a rate of 0.5 $\mu \mathrm{l} / \mathrm{min}$ using $10 \mu \mathrm{l}$ Hamilton syringes driven by a syringe infusion pump (Harvard Apparatus). After infusion, the injectors remained in place for an additional $60 \mathrm{~s}$ to allow diffusion of the drug, and rats were tested 15 min later. For the combination studies of intracranial naloxone/CTAP pretreatment and intraperitoneal amphetamine, directly after removal of the injectors, rats were injected with vehicle or amphetamine $(0.5 \mathrm{mg} / \mathrm{kg})$ and tested 15 min later.

Assessment of cannula placement. After completion of the behavioral procedures, animals were deeply anesthetized using sodium pentobarbital (Ceva Sante Animale BV; $60 \mathrm{mg} / \mathrm{ml}$, i.p.). Subsequently, animals were perfused transcardially with $100 \mathrm{ml}$ of $0.9 \% \mathrm{NaCl}$, followed by $500 \mathrm{ml}$ of $4 \%$ paraformaldehyde in $0.1 \mathrm{M}$ PBS, $\mathrm{pH} 7.2$. Brains were removed rapidly and postfixed for $1 \mathrm{~h}$ in the same fixative at room temperature, and then stored in $5 \%$ sucrose in $0.1 \mathrm{M} \mathrm{PBS}$ at $4^{\circ} \mathrm{C}$. Coronal sections of $35 \mu \mathrm{m}$ were cut on a cryostat and subsequently stained with thionine for the determination of the infusion sites. Only animals with correct cannulae placement were included in the analyses.

Statistical analyses. All data were analyzed using NCSS2007, version 07.1.18 (NCSS). Data were subjected to repeated-measures ANOVA with drug treatment (5-CSRTT, DRT) and delay to large reinforcer (DRT) as
B

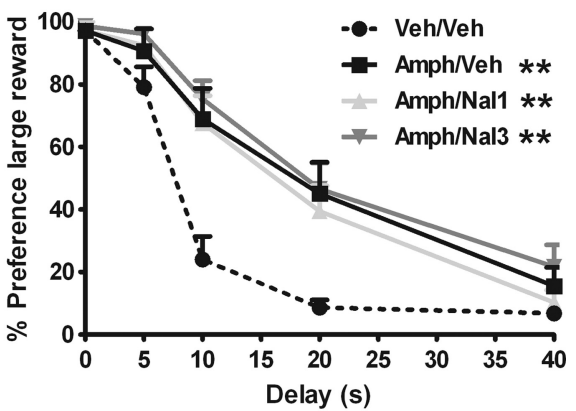
determined using Mauchly's tests for equal variances and in case of violation of homogeneity, Huynh-Feldt $\varepsilon(\varepsilon)$ adjusted degrees of freedom and resulting more conservative probability values were depicted and used for subsequent analyses. In case of statistically significant main effects, additional post hoc comparisons were conducted using Newman-Keuls multiple-comparison tests. The level of probability for statistically significant effects was set at 0.05 . All graphs were produced using GraphPad Prism, version 5.02 for Windows (GraphPad Software).

\section{Results}

\section{Effects of naloxone on amphetamine-induced impulsivity}

To test the putative involvement of endogenous opioids in amphetamine-induced impulsivity, the effects of amphetamine alone and in combination with the opioid receptor antagonist naloxone were studied, first in the 5-CSRTT. Four animals were excluded from the analyses because of consistent high omission rates during baseline training and drug testing ( $>35$ omissions/ session). In line with previous reports (Cole and Robbins, 1987, 1989; van Gaalen et al., 2006a; Pattij et al., 2007), a systemic injection of amphetamine $(0.5 \mathrm{mg} / \mathrm{kg})$ significantly increased premature responding in the 5-CSRTT (Fig. $1 A$ ) and previous administration of naloxone dose-dependently attenuated this effect $\left(F_{(5,55)}=33.22 ; p<0.001 ; \varepsilon=0.879\right)$. Additional comparisons revealed that both naloxone doses attenuated the effects of amphetamine, with a larger effect size of $3.0 \mathrm{mg} / \mathrm{kg}$. This dose reversed the effects of amphetamine on premature responding to the extent that it was statistically not different from vehicle-vehicle treatment ( $p=0.070$ ), although the number of premature responses was still 2.9-fold higher. Importantly, in keeping with previous data, naloxone by itself did not affect premature responding (Pattij et al., 2009), although it is conceivable that the somewhat lower baseline response levels prevented large reductions of response numbers. As summarized in Table 1, significant treatment effects were also observed on accurate choice $\left(F_{(5,55)}=\right.$ $11.06 ; p<0.001)$, with amphetamine reducing the percentage of correct choice and naloxone dose-dependently antagonizing this effect. Amphetamine further decreased correct response latencies $\left(F_{(5,55)}=4.48 ; p=0.002\right)$, and this effect was partially reversed by previous treatment with $3 \mathrm{mg} / \mathrm{kg}$ naloxone as this drug combination did neither differ from vehicle-vehicle nor vehicle-amphetamine treatment. Finally, there was a small but significant treatment effect on perseverative responding $\left(F_{(5,55)}=2.90 ; p=\right.$ $0.044 ; \varepsilon=0.656)$ because of a significant increase thereof after amphetamine in combination with $3 \mathrm{mg} / \mathrm{kg}$ naloxone. No sig- 
Table 1. Effects of $0.5 \mathrm{mg} / \mathrm{kg}$ amphetamine, naloxone, and their combination on measures of attentional function, compulsivity, and motivation in the 5-CSRTT

\begin{tabular}{|c|c|c|c|c|c|}
\hline Treatment & Accuracy (\%) & Perseverative responses & Response latency (ms) & Omissions & Feeder latency (ms) \\
\hline Vehicle-vehicle & $95.0 \pm 0.9$ & $5.9 \pm 1.1$ & $303 \pm 15$ & $8.4 \pm 2.7$ & $1083 \pm 68$ \\
\hline Vehicle-NAL (1 mg/kg) & $94.4 \pm 1.1$ & $5.3 \pm 1.2$ & $293 \pm 13$ & $6.8 \pm 1.5$ & $1120 \pm 89$ \\
\hline Vehicle-NAL (3 mg/kg) & $93.3 \pm 1.2$ & $7.7 \pm 2.2$ & $296 \pm 16$ & $8.9 \pm 2.0$ & $1377 \pm 194$ \\
\hline AMPH-vehicle & $85.9 \pm 1.5^{* *}$ & $7.5 \pm 2.1$ & $265 \pm 10^{*}$ & $8.8 \pm 2.6$ & $1009 \pm 89$ \\
\hline AMPH-NAL (1 mg/kg) & $88.6 \pm 1.5^{* *}$ & $8.8 \pm 2.2$ & $267 \pm 10^{*}$ & $5.9 \pm 0.9$ & $1133 \pm 135$ \\
\hline AMPH-NAL (3 mg/kg) & $92.0 \pm 1.6^{\# \#}$ & $13.9 \pm 3.5^{* \#}$ & $289 \pm 10$ & $9.6 \pm 3.1$ & $1797 \pm 387$ \\
\hline
\end{tabular}

In total, $n=12$ animals were included in the analyses, and data depict mean \pm SEM. AMPH, Amphetamine; NAL, naloxone.

${ }^{*} p<0.05$ and ${ }^{* *} p<0.005$ versus vehicle-vehicle; ${ }^{*} p<0.05$ and ${ }^{\# \#} p<0.005$ compared with AMPH-vehicle.

A

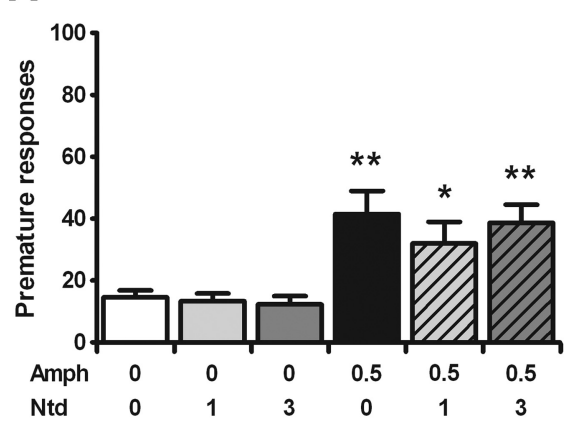

B

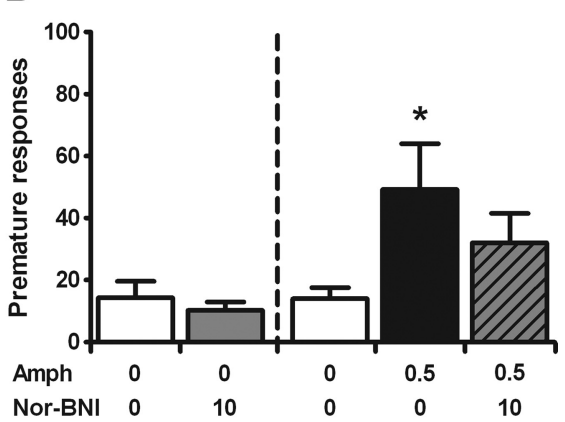

Figure 2. Effects of naloxone on amphetamine-induced inhibitory control deficits are not attributable to blockade of $\delta$ - or $\kappa$-opioid receptors. $\boldsymbol{A}, \boldsymbol{B}$, Effects of amphetamine (Amph), naltrindole (Ntd), nor-BNI, and their combinations on mean ( \pm SEM) number of premature responses made in the 5-CSRTT. In total, $n=16$ and $n=8$ animals were included in the analyses for the Ntd $(\boldsymbol{A})$ and nor-BNI data $(\boldsymbol{B})$, respectively. Drug doses are expressed as milligrams per kilogram. ${ }^{*} p<0.05$ and ${ }^{* *} p<0.005$ versus vehicle-vehicle.

nificant effects of any treatment were observed for the number of errors of omission $(p>0.1)$ or feeder latency $(p>0.05)$.

To test whether opioids also mediate the effects of amphetamine on another form of impulsivity, the effects of amphetamine alone and in combination with naloxone were also studied in the DRT. Two animals were removed from the analysis, one because of failure to show delay-dependent discounting of the large reinforcer, and one because of a consistently high rate of omissions ( $>70 \%$ of trials). As previously observed (Wade et al., 2000; Winstanley et al., 2003, 2005; van Gaalen et al., 2006b), amphetamine in this task reduced impulsive choice as reflected by an increased preference for the larger reinforcer over increasing delays compared with vehicle treatment (dose: $F_{(3,39)}=12.36$, $p<0.001$; dose by delay: $\left.F_{(12,156)}=4.48, p<0.001\right)$. In contrast to what was observed in the 5-CSRTT, however, previous administration of naloxone did not alter the effects of amphetamine in the DRT (Fig. 1B). Together, these results indicate that endogenous opioids are involved in mediating amphetamine-induced impulsivity in the 5-CSRTT, but not the DRT. The detrimental effects of amphetamine on accurate choice in the 5-CSRTT were only significant in the naloxone experiments and the observation that naloxone reversed these effects might suggest opioid involvement. Nonetheless, this notion is not paralleled by opposing effects on this parameter by intracranial infusion of opioid receptor agonists in this study, or systemic morphine as reported previously (Pattij et al., 2009).

\section{Effects of naltrindole and nor-BNI on amphetamine-induced impulsivity}

There are three main classes of opioid receptors in the brain, $\mu-$, $\delta$-, and $\kappa$-opioid receptors, each with their own function and distribution (Mansour et al., 1987, 1995; Waldhoer et al., 2004). Naloxone preferentially blocks $\mu$-opioid receptors but also has affinity for the other opioid receptor subtypes (Schmidhammer et al., 1989; Eguchi, 2004). To study the involvement of $\delta$ - and/or $\kappa$-opioid receptors in amphetamine-induced inhibitory control deficits, the effects of amphetamine alone and in combination with naltrindole and nor-BNI, representing selective $\delta$ - or $\kappa$-opioid receptor antagonists, respectively, were tested in the 5-CSRTT. Naltrindole did not affect amphetamineinduced increments in premature responding in the 5-CSRTT and did not alter inhibitory control when administered by itself (Fig. $2 A)\left(F_{(5,75)}=7.65 ; p<\right.$ $0.001 ; \varepsilon=0.78)$. No significant treatment effects were found on other behavioral parameters in the 5-CSRTT (Table 2) (response latency, $p>0.05$; all other values of $p>0.1$ ). The results obtained with nor-BNI (Fig. $2 B$ ) were more difficult to interpret. nor-BNI in itself did not affect any behavioral parameter in the 5-CSRTT (all values of $p>0.1$ ). Results from the combination experiment with amphetamine and nor-BNI showed that there was an overall effect of treatment on inhibitory control $\left(F_{(2,14)}=4.41 ; p=0.033\right)$. Post hoc analysis showed that amphetamine-induced inhibitory control deficits were not significantly reduced by pretreatment with nor-BNI. However, there was also no significant increase in premature responding with the amphetamine and nor-BNI combination. The latter results may, however, have been confounded as there also was a significant effect of nor-BNI on the number of omissions (Table 2) $\left(F_{(2,14)}=4.11 ; p=0.039\right)$. Post hoc analysis revealed that nor-BNI in combination with amphetamine significantly raised the number of omissions, suggesting a general decrease in responding under this condition. To control for these confounding effects, an additional analysis in which the number of premature responses was expressed as the percentage of total number of responses was performed (for formula, see Materials and Methods). This analysis revealed that there was an overall effect of treatment on premature responding $\left(F_{(2,14)}=7.79 ; p=\right.$ $0.005)$, with amphetamine both alone and in combination with nor-BNI significantly increasing premature responding and no significant difference between the amphetamine and amphetamine/nor-BNI condition (vehicle-vehicle, $11.22 \pm 2.43 \%$ premature responses; amphetamine-vehicle, $25.40 \pm 4.25 \%$; and amphetamine/nor-BNI, $22.72 \pm 4.82 \%)$. There were no additional treatment effects (all values of $p>0.1$ ).

To further examine a role for endogenous opioid systems in regulating amphetamine-induced impulsivity in the DRT, the effects of amphetamine alone and in combination with naltrindole and nor-BNI were tested in this paradigm (Fig. 3). Naltrin- 
Table 2. Effects of $0.5 \mathrm{mg} / \mathrm{kg}$ amphetamine, naltrindole, nor-BNI, and their combinations on measures of attentional function, compulsivity, and motivation in the 5 -CSRTT

\begin{tabular}{|c|c|c|c|c|c|}
\hline Treatment & Accuracy (\%) & Perseverative responses & Response latency (ms) & Omissions & Feeder latency (ms) \\
\hline \multicolumn{6}{|l|}{ Amphetamine-naltrindole } \\
\hline Vehicle-vehicle & $84.5 \pm 2.5$ & $9.6 \pm 1.4$ & $309 \pm 9$ & $11.3 \pm 2.4$ & $1404 \pm 223$ \\
\hline Vehicle-NTD (1 mg/kg) & $85.2 \pm 2.3$ & $11.6 \pm 2.4$ & $301 \pm 10$ & $10.2 \pm 2.4$ & $1168 \pm 155$ \\
\hline Vehicle-NTD (3 mg/kg) & $86.2 \pm 2.8$ & $11.8 \pm 3.5$ & $308 \pm 9$ & $8.8 \pm 1.6$ & $1189 \pm 199$ \\
\hline AMPH-vehicle & $83.3 \pm 1.8$ & $12.1 \pm 3.6$ & $298 \pm 10$ & $12.8 \pm 3.2$ & $1135 \pm 224$ \\
\hline AMPH-NTD (1 mq/kg) & $83.7 \pm 2.1$ & $6.6 \pm 1.9$ & $292 \pm 7$ & $10.5 \pm 2.1$ & $1073 \pm 154$ \\
\hline AMPH-NTD (3 mg/kg) & $81.9 \pm 2.2$ & $12.5 \pm 2.9$ & $284 \pm 9$ & $11.0 \pm 2.9$ & $1665 \pm 431$ \\
\hline \multicolumn{6}{|l|}{ nor-Binaltorphimine alone } \\
\hline Vehicle-vehicle & $89.0 \pm 2.0$ & $10.5 \pm 3.8$ & $290 \pm 8$ & $8.1 \pm 2.0$ & $1369 \pm 427$ \\
\hline Vehicle-nor-BNI (10 mg/kg) & $89.2 \pm 1.6$ & $11.3 \pm 2.5$ & $283 \pm 10$ & $9.0 \pm 1.9$ & $1297 \pm 232$ \\
\hline \multicolumn{6}{|c|}{ Amphetamine-nor-binaltorphimine } \\
\hline Vehicle-vehicle & $89.0 \pm 1.8$ & $5.6 \pm 2.3$ & $267 \pm 12$ & $5.8 \pm 1.0$ & $860 \pm 61$ \\
\hline AMPH-vehicle & $85.6 \pm 2.6$ & $4.0 \pm 1.2$ & $253 \pm 10$ & $6.3 \pm 1.9$ & $730 \pm 80$ \\
\hline AMPH-nor-BNI (10 mg/kg) & $85.2 \pm 2.5$ & $3.0 \pm 0.7$ & $280 \pm 18$ & $14.4 \pm 4.4^{\#}$ & $728 \pm 99$ \\
\hline
\end{tabular}

$n=16$ animals and $n=8$ animals were included in the analyses with NTD and nor-BNI, respectively, and data depict mean \pm SEM. AMPH, Amphetamine; NTD, naltrindole.

${ }^{\#} p<0.05$ compared with AMPH-vehicle.

dole alone did not significantly alter impulsive choice on itself and also did not affect the beneficial effects of amphetamine on impulsive choice (Fig. 3A) (dose: $F_{(3,45)}=18.99, p<0.001$; dose by delay: $F_{(12,180)}=6.05, p<0.001, \varepsilon=$ $0.59)$. In the nor-BNI experiment, one animal unexpectedly died during task acquisition; hence, only 15 animals were tested. Results showed that, similar to naltrindole, nor-BNI alone (Fig. 3B) did not change impulsive decision making (dose and dose by delay main effect: $p>0.1$ ). However, this $\kappa$-opioid receptor antagonist partially reversed the effects of amphetamine in the DRT (Fig. 3C) (dose: $F_{(2,14)}=14.76, p<0.001$; dose by delay: $\left.F_{(8,56)}=3.32, p=0.004\right)$. Together, these data suggest endogenous opioids and presumably $\mu$-opioid receptors mediate amphetamine-induced deficits in inhibitory control, whereas $\kappa$-opioid receptors might be involved in the effects of amphetamine on impulsive decision making.

\section{Effects of naloxone on GBR 12909-induced} impulsivity in the 5-CSRTT

The effects of amphetamine in the brain depend on the function of dopamine, norepinephrine, and serotonin transporters, and as such this psychostimulant acts as an indirect agonist of these monoamine neurotransmitter systems (Seiden et al., 1993; Rothman et al., 2001; Robertson et al., 2009). As it has previously been shown that amphetamine-induced inhibitory control deficits critically depend on increased dopamine transmission (Cole and Robbins, 1987, 1989; van Gaalen et al., 2006a, 2009; Pattij et al., 2007), it was tested whether previous administration of naloxone would also attenuate the effects of the selective dopamine transporter inhibitor GBR 12909 in the 5-CSRTT (van Gaalen et al., 2006a). In this experiment, one animal was excluded from analysis because of a high omission rate under vehicle conditions. As shown in Figure 4, naloxone abolished the detrimental effects of GBR 12909 on inhibitory control $\left(F_{(3,42)}=7.60 ; p<0.001\right)$. There were no significant overall treatment effects on other be-
B
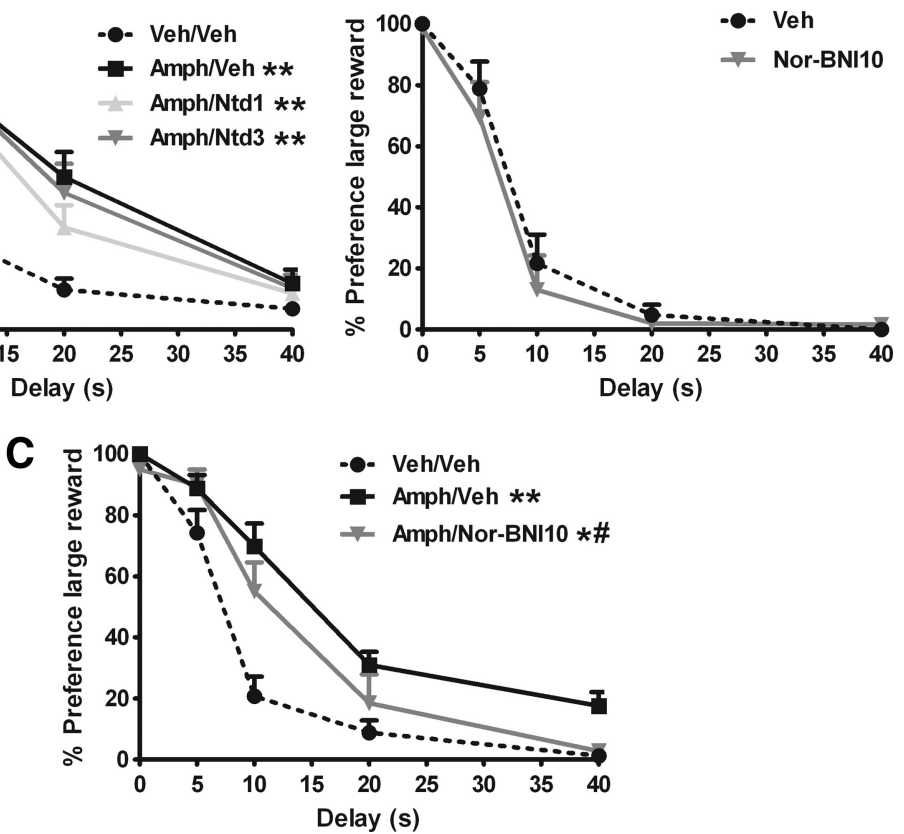

Figure 3. Effects of blockade of $\delta$ - or $\kappa$-opioid receptors on amphetamine-induced reductions in impulsive choice. Effects of amphetamine (Amph), naltrindole (Ntd), nor-BNI, and their combinations on mean ( \pm SEM) percentage preference for the larger, delayed reinforcer in the DRT. $\boldsymbol{A}-\boldsymbol{C}$, In total, $n=16$ and $n=7 / n=8$ animals were included in the analyses for the Ntd $(\boldsymbol{A})$ and nor-BNI $(\boldsymbol{B}, \boldsymbol{C})$ data, respectively. Drug doses are expressed as milligrams per kilogram. ${ }^{*} p<0.05$ and ${ }^{* *} p<0.005$ versus vehicle-vehicle; ${ }^{\#} p<0.05$ compared with amphetamine-vehicle.

havioral parameters (Table 3) (all values of $p>0.1$ ). Thus, it seems that dopamine-induced inhibitory control deficits depend on endogenous opioid signaling presumably via $\mu$-opioid receptor activation.

Effects of intra-nucleus accumbens infusion of naloxone on amphetamine-induced impulsivity in the 5-CSRTT

To find an anatomical locus for endogenous opioid-mediated effects of amphetamine in the 5-CSRTT, effects of naloxone infusion into either the NAc shell or NAc core alone or in combination with a systemic injection of amphetamine were determined. One rat from the NAc core group was excluded from analysis because of cannulae misplacement. Results showed that a systemic injection of amphetamine $(0.5 \mathrm{mg} / \mathrm{kg})$ robustly increased premature responding in both the NAc shell and NAc 


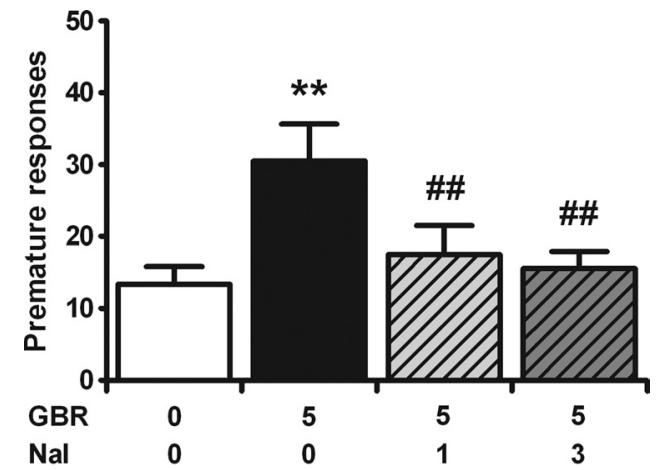

Figure 4. Dopamine-induced inhibitory control deficits can be blocked with naloxone. Effects of GBR 12909 (GBR), naloxone (Nal), and their combination on mean ( \pm SEM) number of premature responses made in the 5-CSRTT. In total, $n=15$ animals were included in the analysis. ${ }^{* *} p<0.005$ versus vehicle-vehicle; ${ }^{\# \#} p<0.005$ compared with GBR 12909 -vehicle.

core group (Fig. 5A,B). However, only in the NAc shell group this detrimental effect was dose-dependently attenuated by previous infusion of naloxone (NAc shell: $F_{(4,36)}=14.01, p<0.001, \varepsilon=$ 0.530 ; NAc core: $\left.F_{(4,32)}=6.11, p<0.001\right)$. Post hoc analyses revealed that both doses of naloxone infused into the NAc shell significantly attenuated amphetamine-induced deficits in inhibitory control with a larger effect size of $5 \mu \mathrm{g}$ of naloxone. This high dose reversed the effects of amphetamine on premature responding to the extent that this statistically did not differ from vehicle-vehicle treatment $(p=0.067)$, although the number of premature responses still was 2.3-fold higher. Data on other parameters in the 5-CSRTT are summarized in Table 4. For both groups, significant treatment effects on accurate choice were found (NAc shell: $F_{(4,36)}=5.07, p=0.002$; NAc core: $F_{(4,32)}=$ $2.90, p=0.037)$. However, post hoc analyses only showed a significant effect in the former group, in which infusion of $5 \mu \mathrm{g}$ of naloxone alone increased accurate choice. With respect to correct response latency, a significant treatment effect was found for the NAc shell group only (NAc shell: $F_{(4,36)}=7.64, p<0.001$; NAc core: $p>0.05)$, with amphetamine decreasing response latencies, an effect that was not altered by naloxone. Furthermore, there was a significant treatment effect on feeder latency in the NAc core group (NAc core: $F_{(4,32)}=3.11, p=0.046, \varepsilon=0.75$; NAc shell: $p>0.1$, which seemed to be related to the highest dose of naloxone as post hoc analyses revealed a trend toward a significant increase in feeder latencies after infusion of $5 \mu \mathrm{g}$ of naloxone alone, and a significant increase after $5 \mu \mathrm{g}$ of naloxone in combination with an amphetamine injection. No significant treatment effects were found for perseverative responding or errors of omission (both NAc shell and core: all values of $p>0.1$ ). Finally, to rule out that any differences in the effects of naloxone observed between the NAc core and shell group were based on differential reactivity to amphetamine between groups, additional analyses were performed with treatment (vehicle-vehicle vs vehicle-amphetamine) as within-subjects factor and infusion site (NAc shell vs NAc core) as between-subjects factor. These analyses revealed no significant site or treatment by site interaction effects except for the parameters correct response latency (site: $F_{(1,17)}=6.63$, $p=0.020$; treatment by site: $p>0.1)$ and number of premature responses (site: $F_{(1,17)}=5.73, p=0.029$; treatment by site: $\left.F_{(1,17)}=7.37, p=0.015\right)$. The latter observation might relate to minor damage to the core region in the NAc shell group because of guide cannulae insertion. Previously, it was found that NAc core and not shell lesions potentiate the effects of amphetamine on premature responding in the 5-CSRTT (Murphy et al., 2008). Subsequent analyses controlling for these infusion group differences by expressing the number of premature responses as a percentage of the total number of responses revealed that there were no significant site or treatment by site interaction effects (both values of $p>0.1$ ), indicating that when controlled for response rate differences both groups reacted similarly to the effects of amphetamine on inhibitory control. Thus, the differential effects of naloxone infusions into the NAc shell and core region on amphetamine-induced premature responding reflect distinct effects of naloxone in both regions rather than differential responsiveness to amphetamine in the two experimental groups. Together, these data reveal that endogenous opioids in the NAc shell, but not NAc core, may mediate amphetamine-induced inhibitory control deficits.

\section{Effects of intra-nucleus accumbens infusion of morphine in the 5-CSRTT}

After completion of the amphetamine and intra-NAc naloxone experiment, the effects of intracranial infusion of the $\mu$-opioid receptor agonist morphine $(2.5 \mu \mathrm{g}$ bilaterally) into the NAc shell and core on impulsivity in the 5-CSRTT were examined in the same groups of animals. Results showed that morphine significantly increased premature responding in the NAc shell, but not NAc core group (Fig. $5 C$ ) (NAc shell: $F_{(1,9)}=6.07, p=0.036$; NAc core: $p>0.1$ ). In addition, as shown in Table 4 , morphine decreased the number of omissions made in the NAc shell group (NAc shell: $F_{(1,9)}=5.78, p=0.04$; NAc core: $p>0.1$ ) and response latencies in the NAc core group (NAc shell: $p>0.1$; NAc core: $\left.F_{(1,8)}=12.76, p=0.008\right)$. Morphine did not cause significant changes in accurate choice, perseverative responding, or feeder latency (both NAc shell and core: all values of $p>0.1$ ). These data indicate that in the NAc shell, unlike the NAc core, activation of most likely $\mu$-opioid receptors is sufficient to impair inhibitory control in rats.

\section{Effects of intra-nucleus accumbens shell infusion of the $\boldsymbol{\mu}$-opioid receptor antagonist CTAP on amphetamine-induced impulsivity in the 5-CSRTT}

To confirm that $\mu$-opioid receptor activation in the NAc shell is critical for amphetamine-induced inhibitory control deficits and promotes these behavioral impairments on itself, two additional experiments were performed. First, the effects of intracranial infusion of the selective $\mu$-opioid receptor antagonist CTAP into the NAc shell alone or combined with systemic amphetamine were determined. In total, two rats were excluded from the analyses because of cannulae misplacement. Amphetamine $(0.5 \mathrm{mg} /$ $\mathrm{kg}$ ) robustly increased premature responding in this group of rats (Fig. 6), and this detrimental effect was attenuated by previous infusion of CTAP $\left(F_{(4,36)}=15.94 ; p<0.001\right)$. Post hoc analyses revealed that both 1 and $3 \mu \mathrm{g}$ CTAP infused into the NAc shell significantly and partially reversed amphetamine-induced deficits in inhibitory control.

Data on other parameters in the 5-CSRTT are summarized in Table 5. Only significant treatment effects were found with respect to accurate choice $\left(F_{(4,36)}=7.49 ; p<0.001\right)$. Here, amphetamine reduced accurate choice, an effect that was completely restored by previous infusion of both CTAP doses into the NAc shell. No significant treatment effects were found for any other behavioral parameter (all values of $p>0.1$ ).

After completion of the amphetamine and intra-NAc shell CTAP experiment, the potent selective $\mu$-opioid receptor agonist DAMGO (0.125 $\mu \mathrm{g}$ bilaterally) was infused into the NAc shell. 
Table 3. Effects of $5 \mathrm{mg} / \mathrm{kg}$ GBR 12909, naloxone, and their combination on measures of attentional function, compulsivity, and motivation in the 5-CSRTT

\begin{tabular}{|c|c|c|c|c|c|}
\hline Treatment & Accuracy (\%) & Perseverative responses & Response latency (ms) & Omissions & Feeder latency (ms) \\
\hline Vehicle-vehicle & $85.0 \pm 1.5$ & $14.4 \pm 2.1$ & $310 \pm 8$ & $9.1 \pm 2.1$ & $1716 \pm 178$ \\
\hline GBR-vehicle & $82.2 \pm 1.9$ & $17.1 \pm 3.9$ & $292 \pm 8$ & $7.7 \pm 1.4$ & $1990 \pm 343$ \\
\hline GBR-NAL (1 mg/kg) & $85.4 \pm 1.7$ & $18.9 \pm 3.8$ & $302 \pm 7$ & $9.2 \pm 2.7$ & $2216 \pm 339$ \\
\hline GBR-NAL (3 mg/kg) & $84.8 \pm 2.1$ & $16.7 \pm 3.3$ & $304 \pm 9$ & $11.5 \pm 2.2$ & $2017 \pm 350$ \\
\hline
\end{tabular}

In total, $n=15$ animals were included in the analyses, and data depict mean \pm SEM. GBR, GBR 12909; NAL, naloxone.

Results showed that DAMGO significantly increased premature responding (Fig. 6) $\left(F_{(1,9)}=17.53 ; p=0.002\right)$. As shown in Table 5, DAMGO did not significantly affect any other behavioral parameter (feeder latency: $p>0.05$; all other values of $p>0.1$ ). Collectively, these data demonstrate that activating $\mu$-opioid receptors in the NAc shell sufficiently impairs inhibitory control and might thus represent a critical step in the neuronal mechanism underlying the effects of amphetamine on inhibitory control in the 5-CSRTT.

\section{Histology}

Figure 7 depicts cannulae placement for animals included in the intracranial infusion experiments. For the amphetamine and naloxone/morphine experiments (Fig. 7A), initially, 20 animals were trained in the 5-CSRTT with cannulae directed at either the NAc shell or core subregion ( $n=10$ each). One individual had to be excluded from the NAc core group, as for this animal histological examination showed cannulae placement outside the borders of the NAc core. For the amphetamine and CTAP/DAMGO experiments (Fig. $7 B$ ), 12 animals were trained in the 5-CSRTT with cannulae directed at the NAc shell subregion. Two individuals were excluded from these experiments because of cannulae placement outside the borders of the NAc shell.

\section{Discussion}

The present results indicate that $\mu$-opioid receptors in the NAc shell and not core region play an important role in amphetamineinduced inhibitory control deficits, probably via an interaction between $\mu$-opioid receptors and mesolimbic DA transmission. In contrast, the beneficial effects of amphetamine on impulsive choice appear independent from opioid signaling.

\section{Opioids, amphetamine, and inhibitory control}

Blocking opioid receptors by naloxone, either peripherally or intracranially in the NAc shell, attenuated amphetamineinduced premature responding in the 5-CSRTT. By contrast, the selective $\delta$ - or $\kappa$-opioid receptor antagonists naltrindole and norBNI did not affect these behavioral effects of amphetamine, indicating involvement of $\mu$-opioid receptors in amphetamineinduced inhibitory control deficits. Indeed, in additional support, intra-NAc shell injections with the highly selective $\mu$-opioid receptor antagonist CTAP also attenuated amphetamine-induced premature responding. The $\mu$-opioid receptor agonists morphine and DAMGO induced premature

B NAc core
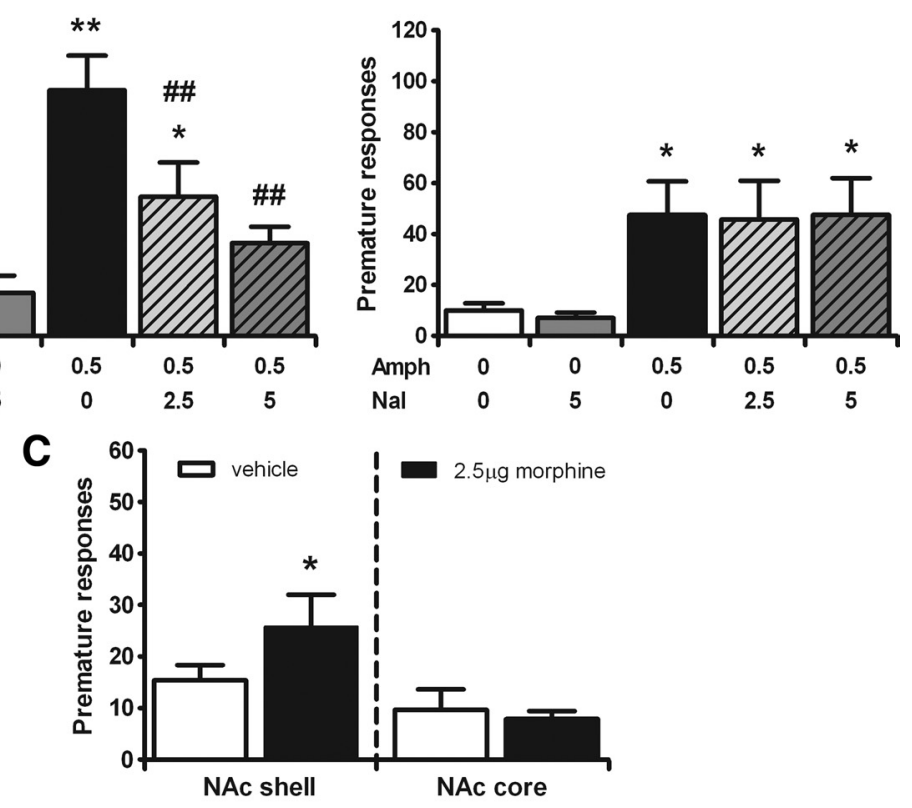

*


Table 4. Effects of $0.5 \mathrm{mg} / \mathrm{kg}$ amphetamine, intracranial naloxone into the NAc shell and NAc core subregions and their combination, or intracranial morphine into the NAc shell and NAc core subregions on measures of attentional function, compulsivity, and motivation in the 5-CSRTT

\begin{tabular}{|c|c|c|c|c|c|}
\hline Treatment (systemic-local) & Accuracy (\%) & Perseverative responses & Response latency (ms) & Omissions & Feeder latency (ms) \\
\hline \multicolumn{6}{|l|}{ NAc shell } \\
\hline Vehicle-vehicle & $79.0 \pm 3.6$ & $12.6 \pm 2.6$ & $368 \pm 15$ & $12.4 \pm 1.5$ & $1948 \pm 270$ \\
\hline Vehicle-NAL $(5.0 \mu \mathrm{g})$ & $87.4 \pm 3.1^{*}$ & $7.3 \pm 1.7$ & $362 \pm 19$ & $20.1 \pm 5.1$ & $2197 \pm 612$ \\
\hline AMPH-vehicle & $75.4 \pm 3.2$ & $8.9 \pm 2.6$ & $321 \pm 15^{*}$ & $12.7 \pm 2.4$ & $2029 \pm 718$ \\
\hline AMPH-NAL $(2.5 \mu \mathrm{g})$ & $80.0 \pm 2.8$ & $10.1 \pm 4.8$ & $306 \pm 11^{* *}$ & $20.7 \pm 5.4$ & $1677 \pm 364$ \\
\hline AMPH-NAL $(5.0 \mu \mathrm{g})$ & $80.9 \pm 3.3$ & $12.9 \pm 6.9$ & $302 \pm 14^{* *}$ & $17.9 \pm 6.5$ & $1911 \pm 522$ \\
\hline Vehicle & $85.2 \pm 2.8$ & $10.5 \pm 2.6$ & $347 \pm 16$ & $12.9 \pm 2.8$ & $1821 \pm 313$ \\
\hline MORPH $(2.5 \mu \mathrm{g})$ & $85.4 \pm 2.1$ & $10.5 \pm 1.6$ & $321 \pm 16$ & $10.0 \pm 2.2^{*}$ & $1336 \pm 217$ \\
\hline \multicolumn{6}{|l|}{ NAc core } \\
\hline Vehicle-vehicle & $85.5 \pm 2.5$ & $8.0 \pm 3.3$ & $319 \pm 8$ & $16.1 \pm 3.8$ & $1441 \pm 278$ \\
\hline Vehicle-NAL $(5.0 \mu \mathrm{g})$ & $86.9 \pm 2.5$ & $16.4 \pm 6.6$ & $312 \pm 9$ & $12.2 \pm 2.0$ & $2419 \pm 742$ \\
\hline AMPH-vehicle & $81.6 \pm 1.9$ & $8.7 \pm 3.9$ & $297 \pm 13$ & $10.2 \pm 2.2$ & $1369 \pm 240$ \\
\hline AMPH-NAL $(2.5 \mu \mathrm{g})$ & $83.1 \pm 3.3$ & $8.0 \pm 3.7$ & $293 \pm 8$ & $9.7 \pm 2.7$ & $1876 \pm 564$ \\
\hline AMPH-NAL $(5.0 \mu \mathrm{g})$ & $79.6 \pm 2.7$ & $29.3 \pm 13.9$ & $290 \pm 8$ & $11.2 \pm 2.7$ & $3822 \pm 1086^{* \#}$ \\
\hline Vehicle & $86.4 \pm 2.2$ & $8.1 \pm 2.0$ & $337 \pm 12$ & $13.6 \pm 3.3$ & $1400 \pm 179$ \\
\hline MORPH $(2.5 \mu \mathrm{g})$ & $88.5 \pm 2.4$ & $6.2 \pm 1.5$ & $310 \pm 8^{*}$ & $9.9 \pm 2.0$ & $1163 \pm 178$ \\
\hline
\end{tabular}

In total, $n=10$ (shell region) and $n=9$ (core region) animals were included in the analyses, and data depict mean \pm SEM. AMPH, Amphetamine; NAL, naloxone; MORPH, morphine.

${ }^{*} p<0.05$ and ${ }^{* *} p<0.005$ versus vehicle-vehicle; ${ }^{\#} p 0.05$ compared with AMPH-vehicle.

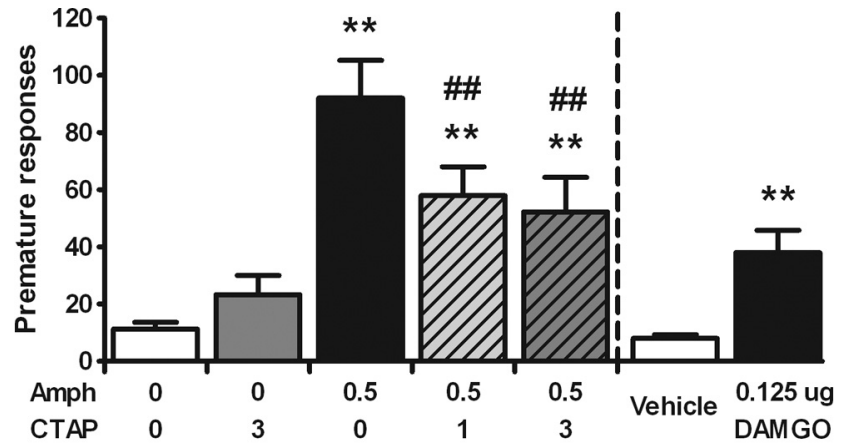

Figure 6. $\mu$-0pioid receptors in the nucleus accumbens shell critically regulate (amphetamine-induced) inhibitory control deficits. Effects of systemic amphetamine (Amph), intracranial CTAP into the NAc shell and their combination, or intra-NAc shell-infused DAMGO on mean ( \pm SEM) number of premature responses made in the 5-CSRTT. In total, $n=10$ animals were included in the data analyses. Amph doses are expressed as milligrams per kilogram, and CTAP and DAMGO doses as micrograms per hemisphere. ${ }^{* *} p<0.005$ versus vehicle or vehicle-vehicle; ${ }^{\# \#} p<0.005$ compared with amphetamine-vehicle.

al., 1997) or, alternatively, is merely a required step potentiating amphetamine-induced DA release (Yoshida et al., 1999; Hirose et al., 2005). Nonetheless, the current data extend previous data showing that acute challenges with psychostimulants such as amphetamine and cocaine activate endogenous opioid systems via DA-dependent mechanisms (Hurd and Herkenham, 1992; Wang and McGinty, 1995, 1996; Olive et al., 2001; RothDeri et al., 2003). Moreover, opioid receptors mediate the effects of amphetamine on DA release and behavioral measures including locomotion, reward, and amphetamineinduced reinstatement of amphetamine seeking (Trujillo et al., 1991; Hooks et al., 1992; Schad et al., 1995; JayaramLindström et al., 2004, 2008; Häggkvist et al., 2009). Particularly the latter finding is of interest in view of the close interrelationship between impulsivity and relapse vulnerability (Perry and Carroll, 2008; Verdejo-García et al., 2008). Thus, opioid receptor antagonists might be effective antirelapse agents because of their beneficial effects on impulsivity.

Given the importance of (NAc) opioid systems in foodmotivated behavior (Kelley et al., 2002; Cota et al., 2006) and amphetamine-induced hyperlocomotion (Hooks et al., 1992;
Schad et al., 1995; Gonzalez-Nicolini et al., 2003), it could be argued that the observed effects of opioid (ant)agonists on (amphetamine-induced) impulsivity might be related to direct effects on food motivated-behavior and/or somatomotor activity. However, this seems very unlikely since none of the tested compounds had clear effects on behavioral measures that could be interpreted as indices of motivation for food, namely errors of omission and feeder latencies. Moreover, systemic administration of naloxone attenuated both amphetamineinduced impulsivity and speeding of response latencies, a parameter reflecting aspects of somatomotor activity in the 5 -CSRTT. Nonetheless, blocking $\mu$-opioid receptors in the NAc shell was found to attenuate amphetamine-induced inhibitory control deficits while simultaneously potentiating rather than reducing amphetamine-induced speeding of response latencies. Collectively, these observations suggest that distinct pathways are mediating the effects of amphetamine on food- and somatomotor-related behaviors.

\section{Opioids, amphetamine, and impulsive choice}

In contrast to its effects on inhibitory control, amphetamine generally reduces impulsive choice as measured in delayed-reward paradigms, primarily via a DA-dependent mechanism (Wade et al., 2000; de Wit et al., 2002; Winstanley et al., 2003, 2005; van Gaalen et al., 2006b). The present results confirm and extend this conclusion by indicating that blocking opioid transmission did not modify the beneficial effects of amphetamine on impulsive decisions. This observation may be somewhat surprising since $\mu$-opioid receptors are positioned to modulate mesolimbic and mesocortical DA transmission. Indeed, morphine activates both aforementioned DA projections (Di Chiara and Imperato, 1988; Devoto et al., 2002), and blocking $\mu$-opioid receptors reduces amphetamine-induced increments in striatal DA release (Hooks et al., 1992; Schad et al., 1995). Furthermore, the current data with nor-BNI and naltrindole suggest that $\delta$ - and $\kappa$-opioid receptors are not involved in (amphetamine-induced) impulsive choice. Pretreatment with nor-BNI somewhat attenuated the beneficial effects of amphetamine on impulsive choice. Nonetheless, the biological relevance of this finding is questionable given that $\kappa$-opioid receptors are well known to negatively modulate mesocorticolimbic DA release (Spanagel et al., 1990; Devine et al., 1993; Margolis et al., 2006), and, hence, blocking $\kappa$-opioid 
Table 5. Effects of $0.5 \mathrm{mg} / \mathrm{kg}$ amphetamine, intracranial CTAP into the NAc shell subregion and their combination, or intracranial DAMGO into the NAc shell subregion on measures of attentional function, compulsivity, and motivation in the 5-CSRTT

\begin{tabular}{|c|c|c|c|c|c|}
\hline Treatment (systemic-local) & Accuracy (\%) & Perseverative responses & Response latency (ms) & Omissions & Feeder latency (ms) \\
\hline Vehicle-vehicle & $86.7 \pm 2.9$ & $12.4 \pm 2.0$ & $334 \pm 11$ & $15.3 \pm 2.1$ & $2016 \pm 351$ \\
\hline Vehicle-CTAP $(3 \mu \mathrm{g})$ & $84.1 \pm 2.5$ & $13.5 \pm 3.7$ & $330 \pm 8$ & $19.0 \pm 3.4$ & $2235 \pm 367$ \\
\hline AMPH-vehicle & $73.7 \pm 3.6^{* *}$ & $11.7 \pm 4.0$ & $321 \pm 14$ & $16.5 \pm 1.6$ & $2274 \pm 483$ \\
\hline AMPH-CTAP $(1 \mu \mathrm{g})$ & $80.2 \pm 3.1^{\#}$ & $8.3 \pm 2.3$ & $317 \pm 10$ & $19.2 \pm 2.5$ & $2227 \pm 499$ \\
\hline AMPH-CTAP $(3 \mu \mathrm{g})$ & $80.9 \pm 2.7^{\#}$ & $7.9 \pm 2.9$ & $351 \pm 13$ & $25.1 \pm 4.2$ & $2037 \pm 525$ \\
\hline Vehicle & $86.7 \pm 2.0$ & $10.2 \pm 3.4$ & $342 \pm 15$ & $14.9 \pm 1.2$ & $2147 \pm 477$ \\
\hline DAMGO $(0.125 \mu \mathrm{g})$ & $84.1 \pm 0.9$ & $10.6 \pm 3.8$ & $339 \pm 19$ & $17.2 \pm 3.4$ & $1759 \pm 461$ \\
\hline
\end{tabular}

In total, $n=10$ animals were included in the analyses, and data depict mean \pm SEM. AMPH, Amphetamine.

${ }^{* *} p<0.005$ versus vehicle-vehicle; ${ }^{*} p<0.05$ compared with AMPH-vehicle.

receptors would be expected to potentiate rather than reduce amphetamineinduced DA release and subsequent impulsive decisions. Interestingly, there is ample evidence linking the opioid system, particularly $\mu$-opioid receptors, to regulation of impulsive decision making (Kieres et al., 2004; Mitchell et al., 2007; Boettiger et al., 2009; Love et al., 2009; Pattij et al., 2009). It can therefore be concluded that (1) psychostimulants alter impulsive choice via opioid-independent mechanisms and (2) opioids may modify this behavior via distinct neuronal mechanisms. Together, our findings lend additional support to the idea that distinct DA pathways modulate inhibitory control and impulsive choice (Winstanley et al., 2006; Pattij and Vanderschuren, 2008). In this regard, it is important to acknowledge that conceptually inhibitory control processes can be further dissected into action restraint (current study) and action cancellation mechanisms, which might rely on partially overlapping circuits and differentially react to drugs such as amphetamine (Feola et al., 2000; de Wit et al., 2002) (for review, see Schachar et al., 2007; Eagle et al., 2008). Consequently, the critical involvement of $\mu$-opioid transmission might not extrapolate to inhibitory control processes involving cancellation of ongoing behavioral responses and this warrants additional investigation.

Nucleus accumbens, opioids, and impulsivity

In line with previous studies (Pattij et al., 2007; Murphy et al., 2008), a differential role for NAc shell and core regions in amphetamine-induced inhibitory control deficits was found here, with a DA-dependent increase in $\mu$-opioid receptor tone being important for the effects of amphetamine in the NAc shell and not core region. The discrepancy between both NAc regions observed here may relate to higher $\mu$-opioid receptor densities in the shell compared with the core region (Dilts and Kalivas, 1989; Pickel et al., 2004). Alternatively, the divergent connectivity of both regions may be critical. Whereas the core region is mainly connected to extrapyramidal motor nuclei, the shell is preferentially embedded within limbic circuitries (Heimer et al., 1991; Berendse et al., 1992). Interestingly, a previous study (Pattij et al., 2007) showed that DA in the NAc core rather than shell is critical for amphetamine-induced premature responding, suggesting that DA receptors mediating amphetamine-induced activation of endogenous opioid systems are located outside the NAc shell. In this respect, it is noteworthy that acute challenges with psychostimulants including amphetamine induce release of the endogenous opioid $\beta$-endorphin, which has high affinity for $\mu$-opioid receptors (Schoffelmeer et al., 1991; Zadina et al., 1997), into the NAc shell (Olive et al., 2001; Roth-Deri et al., 2003; Doron et al., 2006). Interestingly, this phenomenon depends on activation of $\mathrm{D}_{2}$ DA receptors in the hypothalamic arcuate nucleus (Doron et al., 2006), a brain region in which the majority of cell bodies terminating in the NAc are located (Finley et al., 1981). Finally, bearing in mind the widespread distribution of $\mu$-opioid receptors in the brain, it is conceivable that the NAc shell is not the only brain site in which $\mu$-opioid receptors regulate inhibitory control. For instance, efferent brain nuclei such as the ventral pallidum (Napier and 
Mitrovic, 1999) or afferent sites including the ventral tegmental area (Schad et al., 2002) that densely express $\mu$-opioid receptors may play a role in this respect.

\section{Concluding remarks}

In conclusion, the present study reveals that $\mu$-opioid receptor signaling in the NAc shell importantly modulates inhibitory control and the effects of amphetamine thereon. The current study adds to literature suggesting that $\mu$-opioid receptors may be a pharmacotherapeutical target to treat maladaptive impulsivity (Mitchell et al., 2007; Boettiger et al., 2009; Love et al., 2009). Indeed, the preferential $\mu$-opioid receptor antagonist naltrexone has been shown to relieve a variety of impulse control disorders in humans including psychostimulant and alcohol addiction, pathological gambling, binge eating, compulsive sexual behavior, self-injurious behavior, and kleptomania as discussed previously (Boettiger et al., 2009). In view of our data, it may also be worthwhile to investigate the effectiveness of naloxone to treat patient groups suffering from reduced inhibitory control such as ADHD patients.

\section{References}

American Psychiatric Association (2000) Diagnostic and statistical manual of mental disorders, Ed 4, Text Revision. Washington, DC: American Psychiatric Association.

Berendse HW, Galis-de Graaf Y, Groenewegen HJ (1992) Topographical organization and relationship with ventral striatal compartments of prefrontal corticostriatal projections in the rat. J Comp Neurol 316:314-347.

Boettiger CA, Kelley EA, Mitchell JM, D’Esposito M, Fields HL (2009) Now or later? An fMRI study of the effects of endogenous opioid blockade on a decision-making network. Pharmacol Biochem Behav 93:291-299.

Cardinal RN, Pennicott DR, Sugathapala CL, Robbins TW, Everitt BJ (2001) Impulsive choice induced in rats by lesions of the nucleus accumbens core. Science 292:2499-2501.

Christakou A, Robbins TW, Everitt BJ (2004) Prefrontal cortical-ventral striatal interactions involved in affective modulation of attentional performance: implications for corticostriatal circuit function. J Neurosci 24:773-780.

Cole BJ, Robbins TW (1987) Amphetamine impairs the discriminative performance of rats with dorsal noradrenergic bundle lesions on a 5-choice serial reaction time task: new evidence for central dopaminergicnoradrenergic interactions. Psychopharmacology (Berl) 91:458-466.

Cole BJ, Robbins TW (1989) Effects of 6-hydroxydopamine lesions of the nucleus accumbens septi on performance of a 5-choice serial reaction time task in rats: implications for theories of selective attention and arousal. Behav Brain Res 33:165-179.

Cota D, Tschöp MH, Horvath TL, Levine AS (2006) Cannabinoids, opioids and eating behavior: the molecular face of hedonism? Brain Res Rev 51:85-107.

Devine DP, Leone P, Pocock D, Wise RA (1993) Differential involvement of ventral tegmental mu, delta and kappa opioid receptors in modulation of basal mesolimbic dopamine release: in vivo microdialysis studies. J Pharmacol Exp Ther 266:1236-1246.

Devoto P, Flore G, Pira L, Diana M, Gessa GL (2002) Co-release of noradrenaline and dopamine in the prefrontal cortex after acute morphine and during morphine withdrawal. Psychopharmacology (Berl) 160:220-224.

de Wit H, Enggasser JL, Richards JB (2002) Acute administration of D-amphetamine decreases impulsivity in healthy volunteers. Neuropsychopharmacology 27:813-825.

Di Chiara G, Imperato A (1988) Drugs abused by humans preferentially increase synaptic dopamine concentrations in the mesolimbic system of freely moving rats. Proc Natl Acad Sci U S A 85:5274-5278.

Dilts RP, Kalivas PW (1989) Autoradiographic localization of mu-opioid and neurotensin receptors within the mesolimbic dopamine system. Brain Res 488:311-327.

Doron R, Fridman L, Yadid G (2006) Dopamine-2 receptors in the arcuate nucleus modulate cocaine-seeking behavior. Neuroreport 17:1633-1636.

Eagle DM, Bari A, Robbins TW (2008) The neuropsychopharmacology of action inhibition: cross-species translation of the stop-signal and go/ no-go tasks. Psychopharmacology (Berl) 199:439-456.

Eguchi M (2004) Recent advances in selective opioid receptor agonists and antagonists. Med Res Rev 24:182-212.

Elia J, Ambrosini PJ, Rapoport JL (1999) Treatment of attention-deficithyperactivity disorder. N Engl J Med 340:780-788.

Evenden JL (1999) Varieties of impulsivity. Psychopharmacology (Berl) $146: 348-361$

Feola TW, de Wit H, Richards JB (2000) Effects of D-amphetamine and alcohol on a measure of behavioral inhibition in rats. Behav Neurosci 114:838-848.

Fillmore MT, Rush CR, Marczinski CA (2003) Effects of D-amphetamine on behavioral control in stimulant abusers: the role of prepotent response tendencies. Drug Alcohol Depend 71:143-152.

Finley JC, Lindström P, Petrusz P (1981) Immunocytochemical localization of beta-endorphin-containing neurons in the rat brain. Neuroendocrinology 33:28-42.

Gonzalez-Nicolini MV, Berglind W, Cole KS, Keogh CL, McGinty JF (2003) Local $\mathrm{mu}$ and delta opioid receptors regulate amphetamine-induced behavior and neuropeptide mRNA in the striatum. Neuroscience 121: 387-398.

Häggkvist J, Lindholm S, Franck J (2009) The opioid receptor antagonist naltrexone attenuates reinstatement of amphetamine drug-seeking in the rat. Behav Brain Res 197:219-224.

Heimer L, Zahm DS, Churchill L, Kalivas PW, Wohltmann C (1991) Specificity in the projection patterns of accumbal core and shell in the rat. Neuroscience 41:89-125.

Hirose N, Murakawa K, Takada K, Oi Y, Suzuki T, Nagase H, Cools AR, Koshikawa N (2005) Interactions among mu- and delta-opioid receptors, especially putative delta1- and delta2-opioid receptors, promote dopamine release in the nucleus accumbens. Neuroscience 135:213-225.

Hooks MS, Jones DN, Justice JB Jr, Holtzman SG (1992) Naloxone reduces amphetamine-induced stimulation of locomotor activity and in vivo dopamine release in the striatum and nucleus accumbens. Pharmacol Biochem Behav 42:765-770.

Hurd YL, Herkenham M (1992) Influence of a single injection of cocaine, amphetamine or GBR 12909 on mRNA expression of striatal neuropeptides. Brain Res Mol Brain Res 16:97-104.

Jayaram-Lindström N, Wennberg P, Hurd YL, Franck J (2004) Effects of naltrexone on the subjective response to amphetamine in healthy volunteers. J Clin Psychopharmacol 24:665-669.

Jayaram-Lindström N, Konstenius M, Eksborg S, Beck O, Hammarberg A, Franck J (2008) Naltrexone attenuates the subjective effects of amphetamine in patients with amphetamine dependence. Neuropsychopharmacology 33:1856-1863.

Kelley AE, Bakshi VP, Haber SN, Steininger TL, Will MJ, Zhang M (2002) Opioid modulation of taste hedonics within the ventral striatum. Physiol Behav 76:365-377.

Kieres AK, Hausknecht KA, Farrar AM, Acheson A, de Wit H, Richards JB (2004) Effects of morphine and naltrexone on impulsive decision making in rats. Psychopharmacology (Berl) 173:167-174.

Kutcher S, Aman M, Brooks SJ, Buitelaar J, van Daalen E, Fegert J, Findling RL, Fisman S, Greenhill LL, Huss M, Kusumakar V, Pine D, Taylor E, Tyano S (2004) International consensus statement on attention-deficit/ hyperactivity disorder (ADHD) and disruptive behaviour disorders (DBDs): clinical implications and treatment practice suggestions. Eur Neuropsychopharmacol 14:11-28.

Love TM, Stohler CS, Zubieta JK (2009) Positron emission tomography measures of endogenous opioid neurotransmission and impulsiveness traits in humans. Arch Gen Psychiatry 66:1124-1134.

Madden GJ, Petry NM, Badger GJ, Bickel WK (1997) Impulsive and selfcontrol choices in opioid-dependent patients and non-drug-using control participants: drug and monetary rewards. Exp Clin Psychopharmacol 5:256-262.

Mansour A, Khachaturian H, Lewis ME, Akil H, Watson SJ (1987) Autoradiographic differentiation of $\mu, \delta$, and $\kappa$ opioid receptors in the rat forebrain and midbrain. J Neurosci 7:2445-2464.

Mansour A, Fox CA, Akil H, Watson SJ (1995) Opioid-receptor mRNA expression in the rat CNS: anatomical and functional implications. Trends Neurosci 18:22-29.

Margolis EB, Lock H, Chefer VI, Shippenberg TS, Hjelmstad GO, Fields HL 
(2006) Kappa opioids selectively control dopaminergic neurons projecting to the prefrontal cortex. Proc Natl Acad Sci U S A 103:2938-2942.

Mitchell JM, Tavares VC, Fields HL, D’Esposito M, Boettiger CA (2007) Endogenous opioid blockade and impulsive responding in alcoholics and healthy controls. Neuropsychopharmacology 32:439-449.

Moeller FG, Barratt ES, Dougherty DM, Schmitz JM, Swann AC (2001) Psychiatric aspects of impulsivity. Am J Psychiatry 158:1783-1793.

Murphy ER, Robinson ES, Theobald DE, Dalley JW, Robbins TW (2008) Contrasting effects of selective lesions of nucleus accumbens core or shell on inhibitory control and amphetamine-induced impulsive behaviour. Eur J Neurosci 28:353-363.

Napier TC, Mitrovic I (1999) Opioid modulation of ventral pallidal inputs. Ann N Y Acad Sci 877:176-201.

Olive MF, Koenig HN, Nannini MA, Hodge CW (2001) Stimulation of endorphin neurotransmission in the nucleus accumbens by ethanol, cocaine, and amphetamine. J Neurosci 21:RC184(1-5).

Olmstead MC, Ouagazzal AM, Kieffer BL (2009) Mu and delta opioid receptors oppositely regulate motor impulsivity in the signaled nose poke task. PLoS One 4:e4410.

Paine TA, Tomasiewicz HC, Zhang K, Carlezon WA Jr (2007) Sensitivity of the five-choice serial reaction time task to the effects of various psychotropic drugs in Sprague-Dawley rats. Biol Psychiatry 62:687-693.

Pattij T, Vanderschuren LJ (2008) The neuropharmacology of impulsive behaviour. Trends Pharmacol Sci 29:192-199.

Pattij T, Janssen MC, Vanderschuren LJ, Schoffelmeer AN, van Gaalen MM (2007) Involvement of dopamine D1 and D2 receptors in the nucleus accumbens core and shell in inhibitory response control. Psychopharmacology (Berl) 191:587-598.

Pattij T, Schetters D, Janssen MC, Wiskerke J, Schoffelmeer AN (2009) Acute effects of morphine on distinct forms of impulsive behavior in rats. Psychopharmacology (Berl) 205:489-502.

Paxinos G, Watson C (1998) The rat brain in stereotaxic coordinates. Sydney: Academic.

Perry JL, Carroll ME (2008) The role of impulsive behavior in drug abuse. Psychopharmacology (Berl) 200:1-26.

Pickel VM, Chan J, Kash TL, Rodríguez JJ, MacKie K (2004) Compartmentspecific localization of cannabinoid 1 (CB1) and mu-opioid receptors in rat nucleus accumbens. Neuroscience 127:101-112.

Robbins TW (2002) The 5-choice serial reaction time task: behavioural pharmacology and functional neurochemistry. Psychopharmacology (Berl) 163:362-380.

Robertson SD, Matthies HJ, Galli A (2009) A closer look at amphetamineinduced reverse transport and trafficking of the dopamine and norepinephrine transporters. Mol Neurobiol 39:73-80.

Roth-Deri I, Zangen A, Aleli M, Goelman RG, Pelled G, Nakash R, GispanHerman I, Green T, Shaham Y, Yadid G (2003) Effect of experimenterdelivered and self-administered cocaine on extracellular beta-endorphin levels in the nucleus accumbens. J Neurochem 84:930-938.

Rothman RB, Baumann MH, Dersch CM, Romero DV, Rice KC, Carroll FI, Partilla JS (2001) Amphetamine-type central nervous system stimulants release norepinephrine more potently than they release dopamine and serotonin. Synapse 39:32-41.

Schachar R, Logan GD, Robaey P, Chen S, Ickowicz A, Barr C (2007) Restraint and cancellation: multiple inhibition deficits in attention deficit hyperactivity disorder. J Abnorm Child Psychol 35:229-238.

Schad CA, Justice JB Jr, Holtzman SG (1995) Naloxone reduces the neurochemical and behavioral effects of amphetamine but not those of cocaine. Eur J Pharmacol 275:9-16.

Schad CA, Justice JB Jr, Holtzman SG (2002) Endogenous opioids in dopaminergic cell body regions modulate amphetamine-induced increases in extracellular dopamine levels in the terminal regions. J Pharmacol Exp Ther 300:932-938.

Schmidhammer H, Burkard WP, Eggstein-Aeppli L, Smith CF (1989) Synthesis and biological evaluation of 14-alkoxymorphinans. 2. (-)-N(cyclopropylmethyl)-4,14-dimethoxymorphinan-6-one, a selective mu opioid receptor antagonist. J Med Chem 32:418-421.
Schoffelmeer AN, Warden G, Hogenboom F, Mulder AH (1991) Beta-endorphin: a highly selective endogenous opioid agonist for presynaptic mu opioid receptors. J Pharmacol Exp Ther 258:237-242.

Seiden LS, Sabol KE, Ricaurte GA (1993) Amphetamine: effects on catecholamine systems and behavior. Annu Rev Pharmacol Toxicol 33:639-677.

Shannon HE, Eberle EL, Mitch CH, McKinzie DL, Statnick MA (2007) Effects of kappa opioid receptor agonists on attention as assessed by a 5 -choice serial reaction time task in rats. Neuropharmacology 53: 930-941.

Spanagel R, Herz A, Shippenberg TS (1990) The effects of opioid peptides on dopamine release in the nucleus accumbens: an in vivo microdialysis study. J Neurochem 55:1734-1740.

Svingos AL, Moriwaki A, Wang JB, Uhl GR, Pickel VM (1997) $\mu$-Opioid receptors are localized to extrasynaptic plasma membranes of GABAergic neurons and their targets in the rat nucleus accumbens. J Neurosci 17:2585-2594.

Trujillo KA, Belluzzi JD, Stein L (1991) Naloxone blockade of amphetamine place preference conditioning. Psychopharmacology (Berl) 104:265-274.

Vanderschuren LJ, Schmidt ED, De Vries TJ, Van Moorsel CA, Tilders FJ, Schoffelmeer AN (1999) A single exposure to amphetamine is sufficient to induce long-term behavioral, neuroendocrine, and neurochemical sensitization in rats. J Neurosci 19:9579-9586.

van Gaalen MM, Brueggeman RJ, Bronius PF, Schoffelmeer AN, Vanderschuren LJ (2006a) Behavioral disinhibition requires dopamine receptor activation. Psychopharmacology (Berl) 187:73-85.

van Gaalen MM, van Koten R, Schoffelmeer AN, Vanderschuren LJ (2006b) Critical involvement of dopaminergic neurotransmission in impulsive decision making. Biol Psychiatry 60:66-73.

van Gaalen MM, Unger L, Jongen-Rêlo AL, Schoemaker H, Gross G (2009) Amphetamine decreases behavioral inhibition by stimulation of dopamine D-2, but not D-3, receptors. Behav Pharmacol 20:484-491.

Verdejo-García A, Lawrence AJ, Clark L (2008) Impulsivity as a vulnerability marker for substance-use disorders: review of findings from high-risk research, problem gamblers and genetic association studies. Neurosci Biobehav Rev 32:777-810.

Wade TR, de Wit H, Richards JB (2000) Effects of dopaminergic drugs on delayed reward as a measure of impulsive behavior in rats. Psychopharmacology (Berl) 150:90-101.

Waldhoer M, Bartlett SE, Whistler JL (2004) Opioid receptors. Annu Rev Biochem 73:953-990.

Wang JQ, McGinty JF (1995) Alterations in striatal zif/268, preprodynorphin and preproenkephalin mRNA expression induced by repeated amphetamine administration in rats. Brain Res 673:262-274.

Wang JQ, McGinty JF (1996) D1 and D2 receptor regulation of preproenkephalin and preprodynorphin mRNA in rat striatum following acute injection of amphetamine or methamphetamine. Synapse 22:114-122.

Winstanley CA, Dalley JW, Theobald DE, Robbins TW (2003) Global 5-HT depletion attenuates the ability of amphetamine to decrease impulsive choice on a delay-discounting task in rats. Psychopharmacology (Berl) 170:320-331.

Winstanley CA, Theobald DE, Dalley JW, Robbins TW (2005) Interactions between serotonin and dopamine in the control of impulsive choice in rats: therapeutic implications for impulse control disorders. Neuropsychopharmacology 30:669-682.

Winstanley CA, Eagle DM, Robbins TW (2006) Behavioral models of impulsivity in relation to ADHD: translation between clinical and preclinical studies. Clin Psychol Rev 26:379-395.

Yoshida Y, Koide S, Hirose N, Takada K, Tomiyama K, Koshikawa N, Cools AR (1999) Fentanyl increases dopamine release in rat nucleus accumbens: involvement of mesolimbic mu- and delta-2-opioid receptors. Neuroscience 92:1357-1365.

Zacny JP, de Wit H (2009) The prescription opioid, oxycodone, does not alter behavioral measures of impulsivity in healthy volunteers. Pharmacol Biochem Behav 94:108-113.

Zadina JE, Hackler L, Ge LJ, Kastin AJ (1997) A potent and selective endogenous agonist for the mu-opiate receptor. Nature 386:499-502. 